\title{
Role of Cdx2 and cell polarity in cell allocation and specification of trophectoderm and inner cell mass in the mouse embryo
}

\author{
Agnieszka Jedrusik, ${ }^{1}$ David-Emlyn Parfitt, ${ }^{1}$ Guoji Guo, ${ }^{2,3}$ Maria Skamagki, ${ }^{1}$ Joanna B. Grabarek, ${ }^{1,5}$ \\ Martin H. Johnson, ${ }^{4}$ Paul Robson, ${ }^{2,3}$ and Magdalena Zernicka-Goetz ${ }^{1,6}$ \\ ${ }^{1}$ Wellcome Trust/Cancer Research UK Gurdon Institute, Cambridge CB2 1QN, United Kingdom; ${ }^{2}$ Stem Cell \\ and Developmental Biology, Genome Institute of Singapore, Singapore 138672; ${ }^{3}$ Department of Biological Sciences, \\ National University of Singapore, Singapore 117543; ${ }^{4}$ Department of Physiology, Development and Neuroscience, \\ University of Cambridge, Cambridge CB2 3DY, United Kingdom
}

Genesis of the trophectoderm and inner cell mass (ICM) lineages occurs in two stages. It is initiated via asymmetric divisions of eight- and 16-cell blastomeres that allocate cells to inner and outer positions, each with different developmental fates. Outside cells become committed to the trophectoderm at the blastocyst stage through $C d \times 2$ activity, but here we show that $C d x 2$ can also act earlier to influence cell allocation. Increasing $C d x 2$ levels in individual blastomeres promotes symmetric divisions, thereby allocating more cells to the trophectoderm, whereas reducing $C d x 2$ promotes asymmetric divisions and consequently contribution to the ICM. Furthermore, both Cdx2 mRNA and protein levels are heterogeneous at the eight-cell stage. This heterogeneity depends on cell origin and has developmental consequences. $\mathrm{Cdx} 2$ expression is minimal in cells with unrestricted developmental potential that contribute preferentially to the ICM and is maximal in cells with reduced potential that contribute more to the trophectoderm. Finally, we describe a mutually reinforcing relationship between cellular polarity and $\mathrm{Cdx} 2$ : $\mathrm{Cdx} 2$ influences cell polarity by up-regulating aPKC, but cell polarity also influences Cdx2 through asymmetric distribution of $C d \times 2$ mRNA in polarized blastomeres. Thus, divisions generating inside and outside cells are truly asymmetric with respect to cell fate instructions. These two interacting effects ensure the generation of a stable outer epithelium by the blastocyst stage.

[Keywords: Cdx2; mouse embryo; polarization; ICM; blastocyst; trophectoderm]

Supplemental material is available at http://www.genesdev.org.

Received May 5, 2008; revised version accepted August 6, 2008.

The first cell fate decision in early mouse development is whether to become the pluripotent inner cell mass (ICM) or an extra-embryonic tissue, the trophectoderm. The genesis of these two lineages appears to occur in two stages. First, cells are allocated to different inside and outside positions via asymmetric divisions. Outer cells may divide asymmetrically, to generate one outer and one inner daughter cell, or symmetrically, in which case both daughters remain outside. There are two waves of these a/symmetric divisions: one at the eight- to 16-cell stage transition and the other at the 16- to 32-cell stage. Then, the cells in these different positions become specified-they become committed to restricted developmen-

\footnotetext{
${ }^{5}$ Present address: University of Manchester, Manchester, United King dom.

${ }^{6}$ Corresponding author.

E-MAIL mzg@mole.bio.cam.ac.uk; FAX 441223634089.

Article is online at http://www.genesdev.org/cgi/doi/10.1101/gad.486108.
}

tal fates. This involves interactions between different transcription factors that specify trophectoderm and ICM cell fate (Johnson and McConnell 2004; Rossant 2004; Zernicka-Goetz 2004). Two hypotheses have been put forward to explain how inside and outside cells might start to differ from each other. The first stresses the importance of cell position (the "inside-outside" hypothesis, Tarkowski and Wroblewska 1967). Thus, when the positions of cells are changed, they develop according to their new position. The second hypothesis stems from the discovery that cells become polarized along the apical-basal axis at the eight-cell stage (Ziomek and Johnson 1981). When the polarized cells divide, outside cells inherit different cellular components than inside cells. Thus, in this second hypothesis it is cell division, rather than cell position, that initiates the generation of the different characteristics of the two cell types. More recently, it has been shown that the same molecules that regulate cell polarity in a variety of systems, including 
aPKC and Par3, also regulate, and are essential for, polarization of mouse blastomeres at the eight-cell stage (Plusa et al. 2005a). However, an important question that has remained unanswered is whether, and if so, how, cell position or cell polarization might affect the expression of those genes that specify the first cell fate decisions in the mouse embryo.

The decision to form the trophectoderm reflects the first tip of the balance away from the pluripotent state. Pluripotency is ensured in blastomeres through the expression of the Oct4 and Sox2 transcription factors that together promote the expression of Nanog (Avilion et al. 2003; Niwa et al. 2005; Smith 2005; Strumpf et al. 2005). Another transcription factor, $\mathrm{Cdx} 2$, appears to play a key role in trophectoderm specification, and its expression may in turn be regulated by the transcriptional regulator TEAD4 (Yagi et al. 2007; Nishioka et al. 2008). Cdx2 expression is important for down-regulating the expression of Oct4 and Nanog (Strumpf et al. 2005), and by the mature blastocyst stage, the distribution of these proteins has become spatially restricted such that Sox2, Oct4, and Nanog proteins are restricted to the ICM, while Cdx2 protein is found only in the trophectoderm. Indeed, in the complete absence of $\mathrm{Cdx} 2$, trophectoderm cell identity cannot be maintained in the blastocyst (Strumpf et al. 2005). It has been recently reported that the Oct4, Sox2, and Nanog proteins are initially expressed in both the inside and outside cells of the embryo (Dietrich and Hiiragi 2007; Ralston and Rossant 2008). This has raised the question of how the spatial separation and restriction of expression patterns of these cell fate-determining transcription factors is regulated. This important question needs to be further addressed in the specific context of the onset of cell polarity and the asymmetric cell divisions.

The initiation of $\mathrm{Cdx} 2$ protein expression is heterogeneous among blastomeres at the eight-cell stage (Dietrich and Hiiragi 2007; Ralston and Rossant 2008). Although it has been suggested that this heterogeneity develops at random (Dietrich and Hiiragi 2007), the possibility that it may be influenced systematically in some blastomeres has not been excluded. For example, might the heterogeneity of $C d x 2$ among blastomeres be influenced by specific orientations of early cleavage divisions? Several studies have shown that the way in which the zygote is partitioned by these early cleavages can influence whether a blastomere will take more symmetric or asymmetric divisions and thereby influence the allocation of its progeny to different lineages and their developmental potential (Gardner 2001, 2002, 2007; Piotrowska and Zernicka-Goetz 2001; Piotrowska et al. 2001; Piotrowska-Nitsche and Zernicka-Goetz 2005; Piotrowska-Nitsche et al. 2005; Torres-Padilla et al. 2007; Bischoff et al. 2008). Viewed in this context, it is an open question whether the heterogeneity in the onset of $C d x 2$ expression occurs at random or is lineage-related (depends on cell origin). Finally, it remains unknown whether this early expression of $C d x 2$ is simply noise or whether it provides a signal important for development, for example, by affecting the subsequent type of cell di- vision and thus allocation of cells to the inside versus outside populations that will form distinct lineages.

Here, we report a role for $C d x 2$ in reinforcing cell polarity: Cells in which $C d x 2$ levels are elevated prior to the generation of inside cells undertake more symmetric divisions and, consequently, contribute a greater proportion of their progeny to the trophectoderm than to the ICM. Conversely, the proportion of cells contributing to the trophectoderm is reduced following down-regulation of $C d x 2$. Thus, the level of $C d x 2$ expression before the inside cell population is set apart can influence cell allocation to inside and outside positions and thereby cell fate at later stages. Examination of the natural variation of $C d x 2$ levels among cells reveals that it depends on how the zygote becomes partitioned by early cleavage divisions. When the division of the second dividing twocell blastomere separates animal (A) from vegetal (V) material, its progeny express $C d x 2$ mRNA and protein significantly more abundantly than do blastomeres resulting from divisions parallel to the animal-vegetal (AV) axis, thus inheriting material from both poles of the zygote. Taken together, these findings add molecular and mechanistic insights to previous demonstrations that such cells contribute significantly more to the trophectoderm than to the ICM and are less pluripotent in embryological assays (Piotrowska-Nitsche et al. 2005; Bischoff et al. 2008). They also provide some insight into the long-standing question of why, in normal development, some blastomeres divide symmetrically while others take asymmetric divisions. These findings led us to investigate how interdependent events before and after the development of cellular polarity at the eight-cell stage might influence allocation of cells to inner and outer positions and subsequently to commitment as ICM and trophectoderm. Thus, we describe a mutually reinforcing relationship between cellular polarity and expression of $C d \times 2$ : $C d x 2$ can influence cell polarity by up-regulating aPKC and stabilizing the polar phenotype, but $\mathrm{Cdx} 2$ distribution can also be influenced by cell polarity to ensure the localization of its mRNA to the outer blastomeres. We propose that the two mutually reinforcing processes of cell polarity and polarized distribution of $C d x 2$ transcripts facilitate the generation of a stable outer epithelium by the blastocyst stage, whereupon $\mathrm{Cdx} 2$ would exert its role to repress the expression of pluripotency genes, leading to commitment of ICM and trophectoderm fates.

\section{Results}

Cells expressing elevated $\mathrm{Cdx} 2$ make an increased contribution to the trophectoderm

The earliest stage at which $\mathrm{Cdx} 2$ is expressed might indicate the first time in development when its influence is felt. Therefore, we examined the expression pattern of $\mathrm{Cdx} 2$ protein throughout preimplantation development by immunofluorescence (Supplemental Fig. 1). This revealed $\mathrm{Cdx} 2$ to be present in a small, variable number of nuclei that increased from the early to late eight-cell stage as reported recently (Dietrich and Hiiragi 2007; 
Ralston and Rossant 2008). By the late blastocyst stage, $\mathrm{Cdx} 2$ was detected only in the trophectoderm (Supplemental Fig. 1G). This natural heterogeneity in $\mathrm{Cdx} 2$ among blastomeres at the eight-cell stage led us to investigate whether the level of early $\mathrm{Cdx} 2$ expression might have any developmental consequence. To address this, we modulated experimentally the level of Cdx2 in just half of the embryo, before asymmetric divisions start at the eight-cell stage, and followed the development to blastocyst. In the first series of experiments, we microinjected $C d \times 2$ mRNA into a single late two-cell or early four-cell blastomere. Because daughter cells from the previous division still retain connections in the latter case, the mRNA transfers between the two cells, resulting in $\mathrm{Cdx} 2$ up-regulation in half of the embryo (Plusa et al. 2005a). The fate of the $C d x 2$ mRNA-injected clone was followed by coinjecting mRNA for DsRed as a lineage marker. In control groups, one late two-cell or early four-cell blastomere was injected with mRNA for DsRed alone. Using these "injection mosaics," we first confirmed that the injection of $C d \times 2$ mRNA, but not of DsRed alone, did indeed elevate the levels of $\mathrm{Cdx} 2$ protein by the eight-cell stage (Fig. 1A,B; Supplemental Fig. 2). The injected embryos were cultured to the 32-cell blastocysts, when cell allocation to inner and outer compartments is completed, and the contribution of the progeny of each clone to the trophectoderm and ICM was analyzed in 3D (Fig. 1C,D; Supplemental Movie 1).

Both $C d x 2$ mRNA-injected and noninjected clones contributed a similar number of cells to the blastocyststage embryo (total number $=625,50 \%$ [312] from the noninjected clone and 50\% [313] from the $C d x 2$ mRNA- injected clone, Fig. 1E). However, elevating $C d x 2$ expression significantly increased the proportional contribution of the clone to the trophectoderm and decreased its contribution to the ICM compared with the noninjected blastomere of the same embryo (Fig. 1C-E). Thus, the $C d x 2$ clone contributed to $38 \%$ of the ICM cells whereas the noninjected, control clone contributed to $62 \%$ of the ICM ( $n=239$ ICM cells; $n=20$ embryos, Mann-Whitney test, $P<0.001$ ) (Fig. 1E; Supplemental Table 1A). Conversely, while $57 \%$ of trophectoderm cells were derived from the $C d \times 2$ clone, the noninjected clone contributed $43 \%$ of trophectoderm cells $(n=386$ trophectoderm cells; Mann-Whitney test, $P<0.001)$. This increased contribution to the trophectoderm and decreased contribution to the ICM was not due to the injection procedure itself, because the injection of DsRed mRNA alone did not lead to any significant changes in the contribution to specific lineages. Thus, the DsRed-expressing clone contributed to $50 \%$ of the trophectoderm and $48 \%$ of the ICM ( $n=19$ embryos, Mann-Whitney test, $P=0.401$ for trophectoderm and $P=0.097$ for ICM) (Fig. 1E; Supplemental Table 1B). This suggests that elevation of $C d x 2$ expression can influence cell allocation and thereby cell fate decisions in the embryo such that cells with a higher level of $C d \times 2$ contribute more cells to the trophectoderm and less to the ICM.

\section{Elevation of $\mathrm{Cdx} 2$ expression increases the frequency of symmetric divisions}

We argued that a greater proportion of $C d x 2$-expressing progeny might contribute to the trophectoderm either as

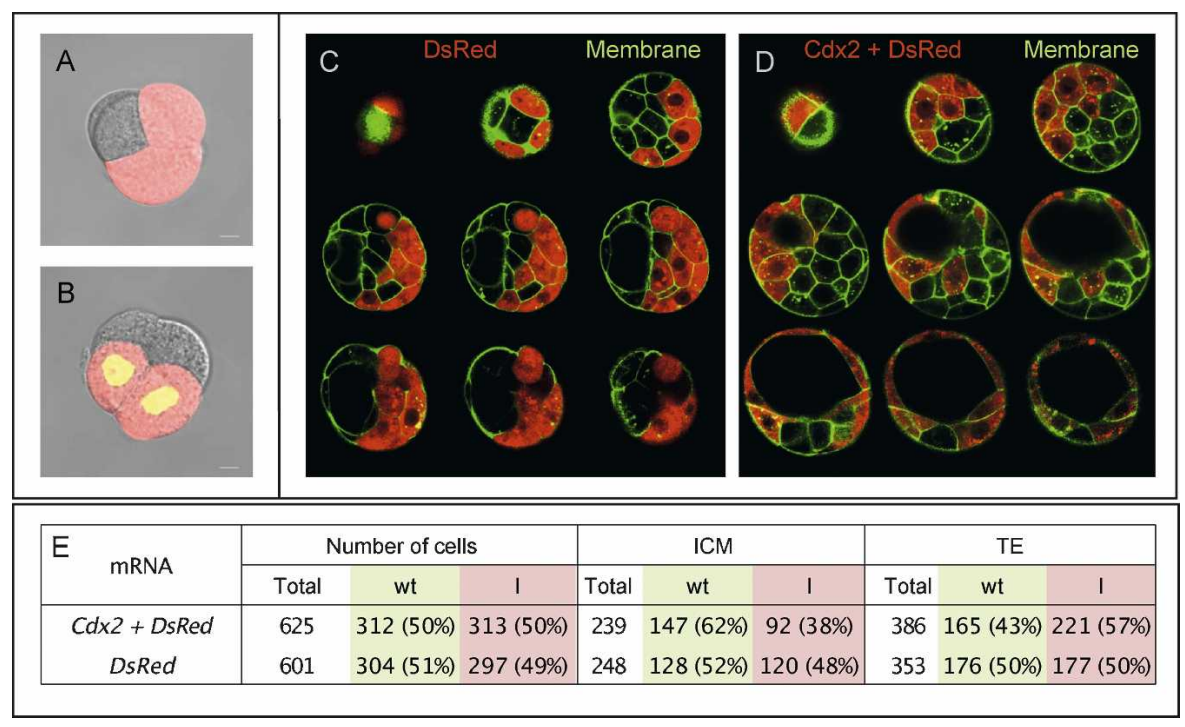

Figure 1. Elevation of $C d x 2$ leads to a greater proportion of cells developing into the trophectoderm. One blastomere of a late two-cell/early four-cell embryo was injected with mRNA for both DsRed and Cdx2, or, in the control, only DsRed mRNA. (A,B) Sections through embryos at the four- to eight-cell transition. (A) In controls, clones from blastomeres injected with DsRed mRNA alone do not show up-regulation of $C d x 2$ protein. $(B) C d \times 2$ mRNA-injected blastomeres show early expression of nuclear Cdx2 protein (green plus red=yellow). Bar, $10 \mu \mathrm{m}$. $(C, D)$. The distribution of the progeny from the injected and noninjected blastomeres was analyzed at the blastocyst stage. In the $C d \times 2$-injected group (red, $D$ ) significantly more progeny contributed to the trophectoderm than in the control group $(C)$. Each panel shows nine individual confocal sections of a blastocyst. (E) Proportion of trophectoderm (TE) and ICM derived from injected (I) and noninjected (wt) clones in the experimental (Cdx2 + DsRed) and control (DsRed control) groups. 
a result of an increased frequency of symmetric divisions to generate more outside cells or due to the migration of an inside cell to the outside after an asymmetric division. To distinguish between these possibilities, we analyzed by time-lapse microscopy the behavior of every cell in the "Cdx2-mosaic" embryos (Fig. 2).

Stacked DIC and fluorescence images were recorded as $4-\mu \mathrm{m}$ serial optical sections at 15 -min intervals. The identification of each cell and its progeny was possible as nuclei were marked by expression of H2B-EGFP (Supplemental Fig. 3; Hadjantonakis and Papaioannou 2004). The $3 \mathrm{D}$ coordinates of every cell in 20 embryos were then traced using SIMI Biocell software, noting the placement of daughter cells in either the outer or inner positions at the beginning and end of the cell cycle, as described previously (Supplemental Movie 2; Bischoff et al. 2008).

The numbers of symmetric and asymmetric divisions were recorded at the fourth cleavage (eight- to 16-cell, the first wave of asymmetric divisions) and, for outer cells only, at the fifth cleavage (16- to 32-cell; the second wave of divisions). In total we scored orientations of 160 divisions for the first wave (73 symmetric and 87 asymmetric) and 225 for the second wave (151 symmetric and 74 asymmetric) in these 20 embryos. The frequency of symmetric divisions was significantly higher in cells expressing elevated levels of $C d x 2$ compared with the noninjected cells in the same embryo. Thus, for the fourth cleavage, as many as $67 \%$ of all symmetric divisions
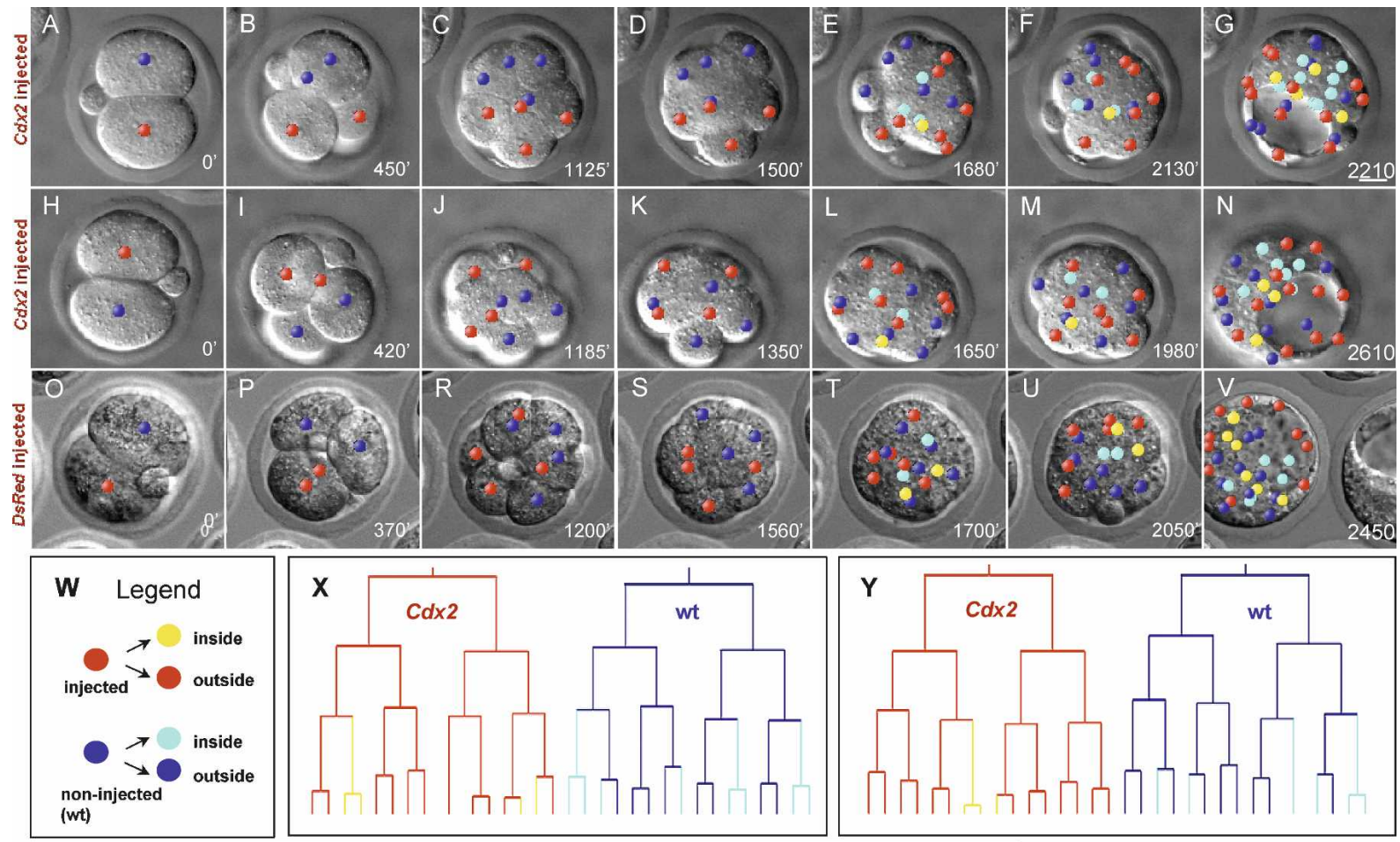

\begin{tabular}{|c|c|c|c|c|c|c|c|c|}
\hline \multirow[t]{5}{*}{ Z } & \multicolumn{2}{|c|}{$\begin{array}{l}\text { Symmetric } \\
\text { First wave }\end{array}$} & \multicolumn{2}{|c|}{$\begin{array}{l}\text { Asymmetric } \\
\text { First wave }\end{array}$} & \multicolumn{2}{|c|}{$\begin{array}{l}\text { Symmetric } \\
\text { Second wave }\end{array}$} & \multicolumn{2}{|c|}{$\begin{array}{l}\text { Asymmetric } \\
\text { Second wave }\end{array}$} \\
\hline & WT & $\begin{array}{l}\text { DsRed } \\
\text { (control) }\end{array}$ & WT & DsRed & WT & DsRed & WT & DsRed \\
\hline & $45 \%$ & $55 \%$ & $51 \%$ & $49 \%$ & $51 \%$ & $49 \%$ & $49 \%$ & $51 \%$ \\
\hline & WT & $\begin{array}{l}\text { Cdx2 } \\
\text { over-exp }\end{array}$ & WT & $\begin{array}{l}\text { Cdx2 } \\
\text { over-exp }\end{array}$ & WT & $\begin{array}{l}\text { Cdx2 } \\
\text { over-exp }\end{array}$ & WT & $\begin{array}{l}\text { Cdx2 } \\
\text { over-exp }\end{array}$ \\
\hline & $33 \%$ & $67 \%$ & $63 \%$ & $37 \%$ & $39 \%$ & $61 \%$ & $57 \%$ & $43 \%$ \\
\hline
\end{tabular}

Figure 2. Elevation of $C d x 2$ expression promotes symmetric divisions. $C d x 2$ was overexpressed in one late two-cell/early four-cell blastomere, and embryos were followed by time-lapse microscopy to the blastocyst stage (two sample embryos shown in $A-G$ and $H-N)$. In controls, DsRed mRNA only was injected $(O-V)$. Lineages were generated with SIMI Biocell software, and the centers of the nuclei from each clone are marked either red (injected clone) or blue (wild-type clone). From 16-cell onward, nuclei of inside cells are marked yellow (injected clone) or light blue (wild-type clone); see $W$ for coding. Cdx2 expression leads to significantly more symmetric than asymmetric divisions (indicated by the relative numbers of yellow versus light blue cells). Merged 3D representations and DIC images from three different embryos are shown in $A-G, H-N$, and $O-V$. Times of images are in minutes. Schematic representation of lineage trees was generated with SIMI Biocell software (X; embryo $A-G$, Y; embryo $H-N)$. (Z) Proportions of symmetric or asymmetric divisions taken by clones expressing injected $C d x 2$ mRNA or DsRed mRNA relative to the clone derived from the noninjected cell (see also Supplemental Table 2). 
were undertaken by $C d x 2$ mRNA-expressing cells, in comparison with only $33 \%$ by cells from the noninjected clone (Mann-Whitney test, $P<0.001$ ) (Fig. 2Z; Supplemental Table 2A). For the fifth cleavage, again the significant majority of symmetric divisions was undertaken by cells of the $C d \times 2$ clone $(61 \%$ vs. $39 \%$ for $C d \times 2$ and wild-type clones, respectively [Fig. 2Z]; Mann-Whitney test $P<0.001$ [Supplemental Table 2A]). For example, the $C d x 2$ clones in the two embryos shown in Figure 2, A-G and $\mathrm{H}-\mathrm{N}$, underwent half as many asymmetric divisions (yellow cells) as the noninjected clone (light-blue cells). This increased occurrence of symmetric versus asymmetric divisions within the treated clone was not due to the injection procedure itself, as injection of DsRed mRNA alone did not lead to significantly different division orientation (Mann-Whitney test, $P=0.187$ for the first wave and $P=0.484$ for the second wave) (Supplemental Table 2B). Comparisons of injected cells between embryos led to a similar result - the frequency of symmetric divisions was significantly elevated in Cdx2-injected clones compared with DsRed-injected clones (Mann-Whitney test, $P=0.048, P=0.003$, for the fourth and fifth divisions, respectively). No examples of internally positioned cells derived from a $C d \times 2$ clone becoming repositioned on the outside were observed. To- gether, these results suggest that the level of $C d x 2$ expression can affect cell allocation to inside or outside positions by a direct or indirect effect on spindle orientation, and that this difference in positional allocation underlies the different relative contributions to the trophectoderm.

\section{Down-regulation of Cdx2 leads to an increased contribution to the ICM}

We next wished to determine whether the down-regulation of $C d x 2$ expression might have the opposite effect on cell distribution within the blastocyst. To this end, we generated a Cdx2-depleted clone within embryos before the allocation of cells to inside positions. We achieved this by injecting $C d \times 2$ dsRNA into single blastomeres of late two- or early four-cell embryos. As before, mRNA for DsRed was coinjected as a lineage marker. Such injection of $C d \times 2$ dsRNA (RNAi) indeed down-regulated the levels of $\mathrm{Cdx} 2$ protein in just half of the embryo (Fig. 3A-H). Embryos were cultured to the 32-cell blastocyst stage, and all of their divisions were scored in time-lapse microscopy before finally being analyzed for the distribution of progeny of each blastomere in the trophectoderm and ICM. Both Cdx2-RNAi and
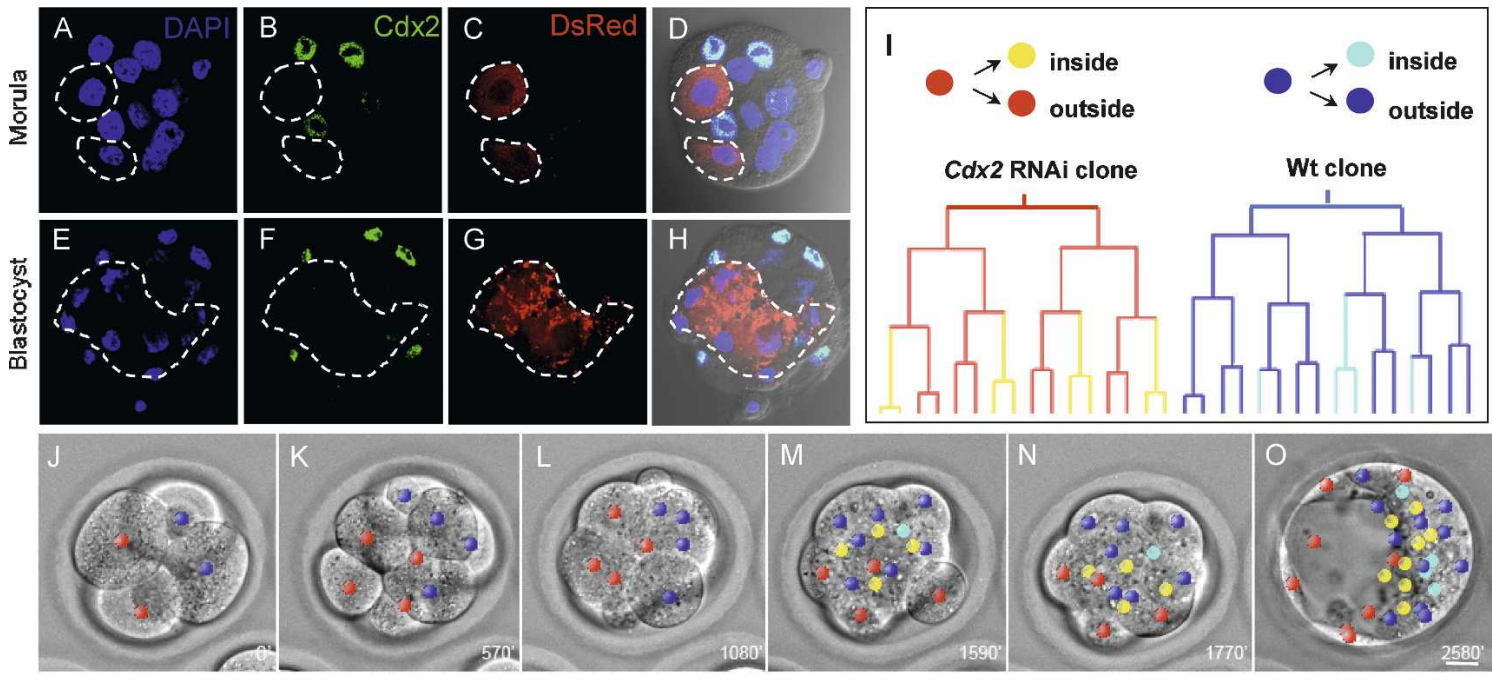

\begin{tabular}{|c|c|c|c|c|c|c|c|}
\hline \multicolumn{2}{|c|}{$\begin{array}{l}\text { Symmetric } \\
\text { First wave }\end{array}$} & \multicolumn{2}{|c|}{$\begin{array}{l}\text { Asymmetric } \\
\text { First wave }\end{array}$} & \multicolumn{2}{|c|}{$\begin{array}{l}\text { Symmetric } \\
\text { Second wave }\end{array}$} & \multicolumn{2}{|c|}{$\begin{array}{l}\text { Asymmetric } \\
\text { Second wave }\end{array}$} \\
\hline WT & $\begin{array}{l}\text { Cdx2 } \\
\text { RNAi }\end{array}$ & WT & $\begin{array}{l}\text { Cdx2 } \\
\text { RNAi }\end{array}$ & WT & $\begin{array}{l}\text { Cdx2 } \\
\text { RNAi }\end{array}$ & WT & $\begin{array}{l}\text { Cdx2 } \\
\text { RNAi }\end{array}$ \\
\hline $60 \%$ & $40 \%$ & $41 \%$ & $59 \%$ & $62 \%$ & $38 \%$ & $49 \%$ & $51 \%$ \\
\hline
\end{tabular}

Figure 3. Down-regulation of $C d \times 2$ expression leads to a reduced contribution to the trophectoderm. $C d x 2$ was down-regulated in half of the embryo by dsRNA injection to one blastomere. $(A-H)$ Sections through fixed and immunocytochemically stained embryos at the morula $(A-D)$ and blastocyst $(E-H)$ stage show specific knockdown of Cdx2 protein in the injected clone; the white dashed line indicates injected cell progeny. $(I)$ Schematic of lineage trees generated with SIMI Biocell software. $(J-O)$ Embryos were followed by time-lapse microscopy to the blastocyst stage. Merged 3D representations and DIC images are shown; times of images are in minutes. Color-coding as in Figure 2. $(P)$ Proportions of symmetric/asymmetric divisions taken by the $C d x 2$ RNAi-injected clone relative to the wild-type clone at fourth and fifth cleavage rounds (see also Supplemental Table 3A). 
noninjected clones contributed a similar number of cells to the blastocyst-stage embryo (total number of cells $=593,51 \%$ [303] from the noninjected clone and 49\% [290] from the Cdx2-RNAi clone).

However, the effects on division a/symmetry and final cell distribution were opposite to those obtained in the $\mathrm{Cdx} 2$ overexpression experiments. We observed a significantly decreased contribution of symmetric divisions (40\% first wave; $38 \%$ second wave) made by the $C d \times 2$ RNAi clone relative to the noninjected clone $160 \%$ first wave; $62 \%$ second wave) (Mann-Whitney test $P<0.001$ for both waves) (Fig. 3P; Supplemental Table 3A). There was an expected reciprocal effect on the contribution of the two clones to asymmetric divisions. Also as expected, on average significantly more of the ICM was derived from the Cdx2-RNAi clone in comparison with the noninjected clone: total number of ICM cells $=227,56 \%(126)$ versus $44 \%$ (101) from Cdx2-RNAi and noninjected clones, respectively (Mann-Whitney, $P<0.001$ ) (Supplemental Table 3B). Conversely, the Cdx2-RNAi clone made a reduced contribution to the trophectoderm (Supplemental Table 3B). As with overexpression experiments, this result was not due to the injection per se as control injection of dsRNA for DsRed does not change the ICM versus trophectoderm contribution, as we showed previously (Plusa et al. 2005a). Together, these results indicate that the consequences of down-regulation of $C d x 2$ upon cell fate in the embryo reciprocate the effects of overexpression. Thus, either a decrease or an elevation in $C d x 2$ expression can influence cell fate such that cells with a higher level of $C d x 2$ contribute more cells to the trophectoderm and do so by increasing the number of symmetric divisions and vice versa for cells with lower $C d x 2$ levels.

\section{Levels of $\mathrm{Cdx} 2$ expression affect the extent of aPKC apical localization}

Previous work has shown that the relative proportions of asymmetric and symmetric divisions can be influenced by the manipulation of the levels of aPKC expression, a protein involved in the genesis of apico-basal polarity at this stage (Plusa et al. 2005a). We therefore examined whether aPKC expression was affected by the level of $C d x 2$. As before, $C d x 2$ mRNA was injected into one late two-cell blastomere, and the distribution of aPKC protein was examined at the four- to eight-cell transition in such mosaic embryos. We found that in all cases $\mid n=17$ embryos) the progeny of the injected cell displayed more extensive and concentrated aPKC protein localization to the apical poles of blastomeres (Fig. 4). This demonstrates that the distribution of aPKC can be influenced by $C d x 2$ expression levels in ways that might explain the differential allocation of cells to inner/outer positions.

\section{Heterogeneity of Cdx2 protein is not random, but relates to cell origin}

Having found that experimental manipulation of the levels of Cdx2 is able to influence the proportion of blastomeres that contribute to the trophectoderm through effects on division symmetry, we investigated whether the natural variation in the level of $\mathrm{Cdx} 2$ expression at the eight-cell stage (Supplemental Fig. 1) might also be associated with specific developmental consequences. To address this question, we first determined whether blastomeres expressing $C d \times 2$ at much higher levels do so at random or with regard to lineage identity. The distinction between these two possibilities requires accurate assessment of the identity of individual eight-cell blastomeres. Although blastomeres cannot be easily distinguished by their overall morphology, their identity can be recognized on the basis of which part of the zygote they inherit. The first division of the zygote is typically along the AV axis, defined by the position of the previous asymmetric meiotic division (marked by the second, attached polar body). Thus, the first division results in blastomeres inheriting both $\mathrm{A}$ and $\mathrm{V}$ components of the zygote. However, at the second cleavage, typically one of the blastomeres undertakes a division more perpendicu-
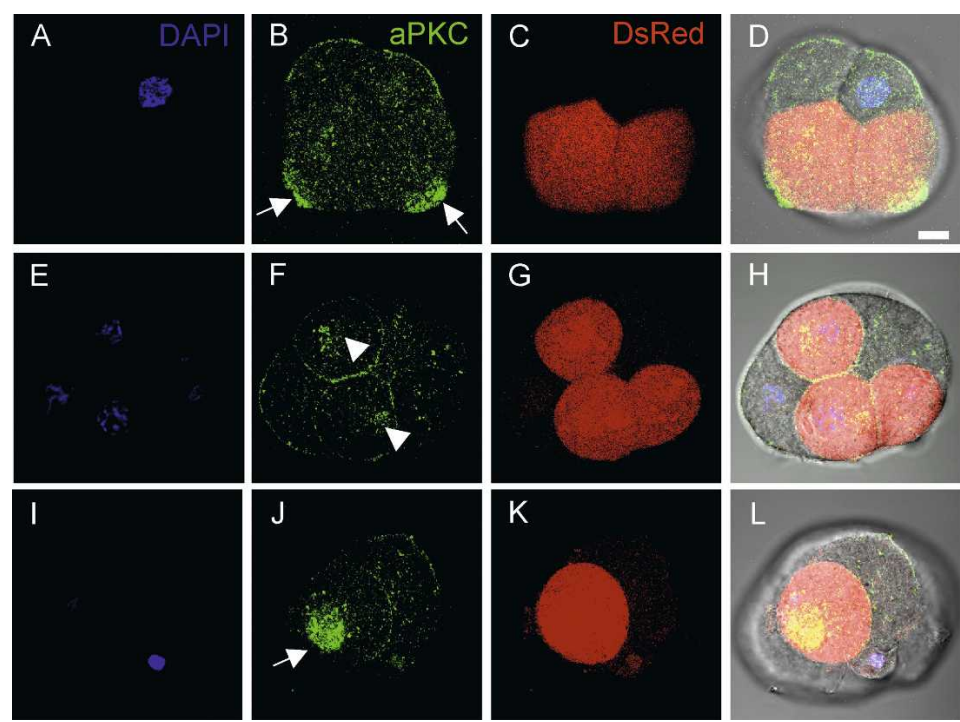

Figure 4. $C d x 2$ influences the extent of aPKC localization. $C d \times 2$ was overexpressed in half of the embryos at the late two-cell stage (DsRed mRNA was coinjected as a lineage marker). Embryos were fixed at the four- to eight-cell transition, immunostained for aPKC (green), and the nuclei stained with DAPI (blue). Examples of two embryos (one shown in $A-D$ and the other shown in $E-L$ ): The first three sets of panels in each row are sections and the last a merged image. White arrows indicate regions of intense aPKC staining within enlarged apical domains in the clone overexpressing $C d x 2$. White arrowheads show aPKC concentrates in the cytoplasm of injected blastomeres. Bar, $10 \mu \mathrm{m}$. 
lar to the $\mathrm{AV}$ axis (equatorial, E), generating blastomeres that have predominantly either A or V components. Thus, different orientations of early cleavage divisions in relation to the AV axis and each other partition A and V components unevenly between four-cell blastomeres (Gardner 2002). Indeed, this has been found to have consequences for development as blastomeres resulting from a later $\mathrm{E}$ division have a significantly compromised developmental potential and reduced levels of a particular epigenetic modification important for expression of pluripotency (Piotrowska-Nitsche et al. 2005; Torres-Padilla et al. 2007). Moreover, their progeny undertake significantly more symmetric divisions and so make a greater contribution to the trophectoderm (Bischoff et al. 2008). Together, these earlier findings suggested the hypothesis that such blastomeres resulting from the later $\mathrm{E}$ division might indeed be the ones in which expression of Cdx2 is elevated.

To address this hypothesis, two-cell embryos were collected, and one blastomere was injected at random with rhodamine dextran. Four-cell embryos were sorted into those in which an $\mathrm{M}$ division preceded an $\mathrm{E}$ division (ME) and vice versa (EM) scored in relation to the attached polar body. They were further sorted according to which of their blastomeres was positive $(+)$ for rhodamine dextran $(\mathrm{M}+\mathrm{E}, \mathrm{ME}+\mathrm{E}+\mathrm{M}$, or $\mathrm{EM}+)$. Groups of similarly classified embryos were fixed 7-8 h after the onset of the eight-cell stage, immunostained for Cdx2 expression, and examined by confocal microscopy. The intensity of staining of each nucleus in every embryo was scored blind-to-group-type by two independent observers as being weak or strong. It was found that blastomeres stained positively more often and more strongly when A and $\mathrm{V}$ parts of the zygote were separated by the second $\mathrm{E}$ division (ME embryos) ( $\chi^{2}$ test, $P=0.004$ ) (Fig. 5; Supplemental Movie 3). This result suggests that the orientation and order of divisions from two to four cells may indeed influence the pattern of the $\mathrm{Cdx} 2$ expression among blastomeres in the eight-cell embryo. Specifically, blastomeres in which the $\mathrm{A}$ and $\mathrm{V}$ parts of the zygote are separated in the ME cleavage pattern showed significantly stronger $\mathrm{Cdx} 2$ expression than all other cells.

\section{Heterogeneity of $\mathrm{Cdx} 2 \mathrm{mRNA}$ is not random, but relates to cell origin}

As it is difficult to quantitate levels of protein expression from immunostaining, we determined whether the effects of the early cleavages upon the level of Cdx2 protein could also be detected at the mRNA level using quantitative TaqMan-based real-time PCR. Levels of $C d \times 2$ transcripts in typed eight-cell blastomeres derived from EM and ME embryos were compared to provide an objective assessment of variation in expression levels. Embryos were carefully classified as ME or EM and the A and the $\mathrm{V}$ blastomeres resulting from $\mathrm{E}$ divisions marked as shown in Figure 6A and its legend. The embryos were then cultured to the mid-eight-cell stage and disaggregated to pairs of cells $(2 / 8)$, which were then sorted according to type (one pair each per embryo of EM-AV1, EM-AV2, EM-A, and EM-V, and one pair each of ME-AV1,
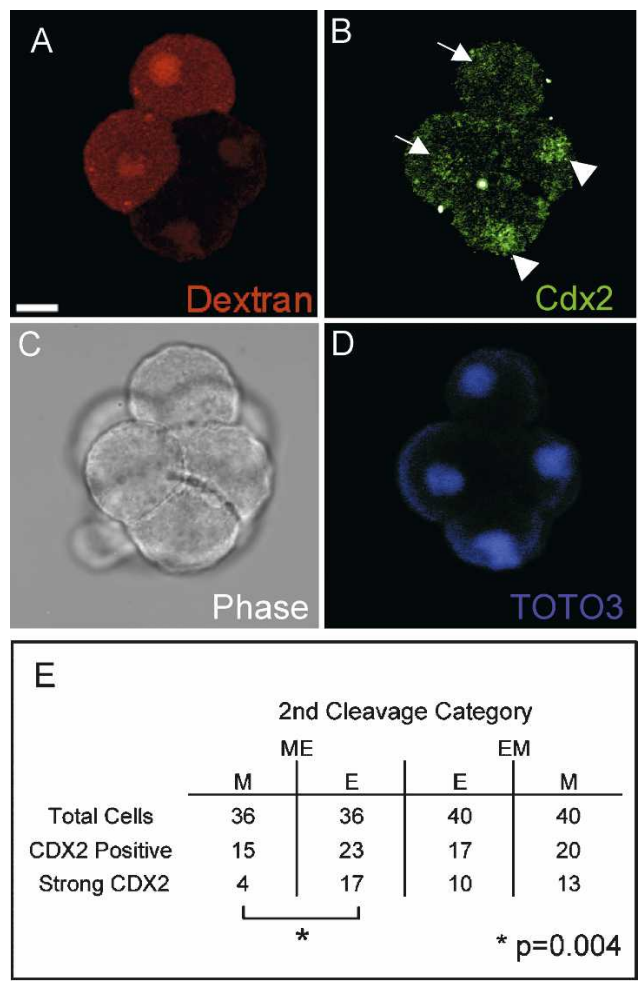

Figure 5. Expression patterns of $\mathrm{Cdx} 2$ protein during development. One two-cell blastomere was injected with rhodamine dextran, and embryos were monitored through division to four cells and sorted into groups according to the sequence of second cleavage division orientations (ME or EM), and which of the dividing cells was positive for dextran. Embryos were then cultured until $7 \mathrm{~h}$ after the onset of the eight-cell stage and stained as in $A$ and $B$. (A) Cytoplasmic rhodamine signal in two of the four eight-cells visible indicates dextran status, which in this example were derived from an M-dividing cell. $(B) \mathrm{Cdx} 2$ expression in the same section, with arrowheads indicating strong nuclear expression in progeny of the E dividing blastomere, and arrows indicating weak expression in their M-derived counterparts. (C) Phase image of the same embryo. (D) DNA stained with TOTO3 in the same plane through the same embryo. $(E)$ Blastomeres in nine ME and 10 EM embryos (making 72 and 80 blastomeres, respectively) were scored for Cdx2 expression status as negative, weak, or strong by two independent scorers who were blind to the origin of embryos and each other's score. The cumulative score for all cells is shown. The only cross-comparison showing a significant difference was between M- and E-derived strongly staining blastomeres from $\mathrm{ME}$ embryos $(P=0.004$; fourfold $\chi^{2}$ test, $\mathrm{df}=1$ ). Bar, $10 \mu \mathrm{m}$.

ME-AV2, ME-A, and ME-V). A total of 14 EM-AV pairs, seven EM-A pairs, and seven EM-V pairs was analyzed, the corresponding numbers for ME pairs being 20,10 , and 10. RNA from each pair of blastomeres was isolated, and the levels of $C d \times 2$ mRNA were normalized against Oct4 mRNA levels in the same cell extract and expressed as a ratio. As controls, mRNAs for two ICM marker genes (Sall4 and Esrrb) isolated from the same cells were also expressed as a ratio relative to Oct4 mRNA levels. Thus, $682 / 8$ blastomere pairs were individually analyzed for a total of 816 PCR reactions. Clustering AV pairs and, 


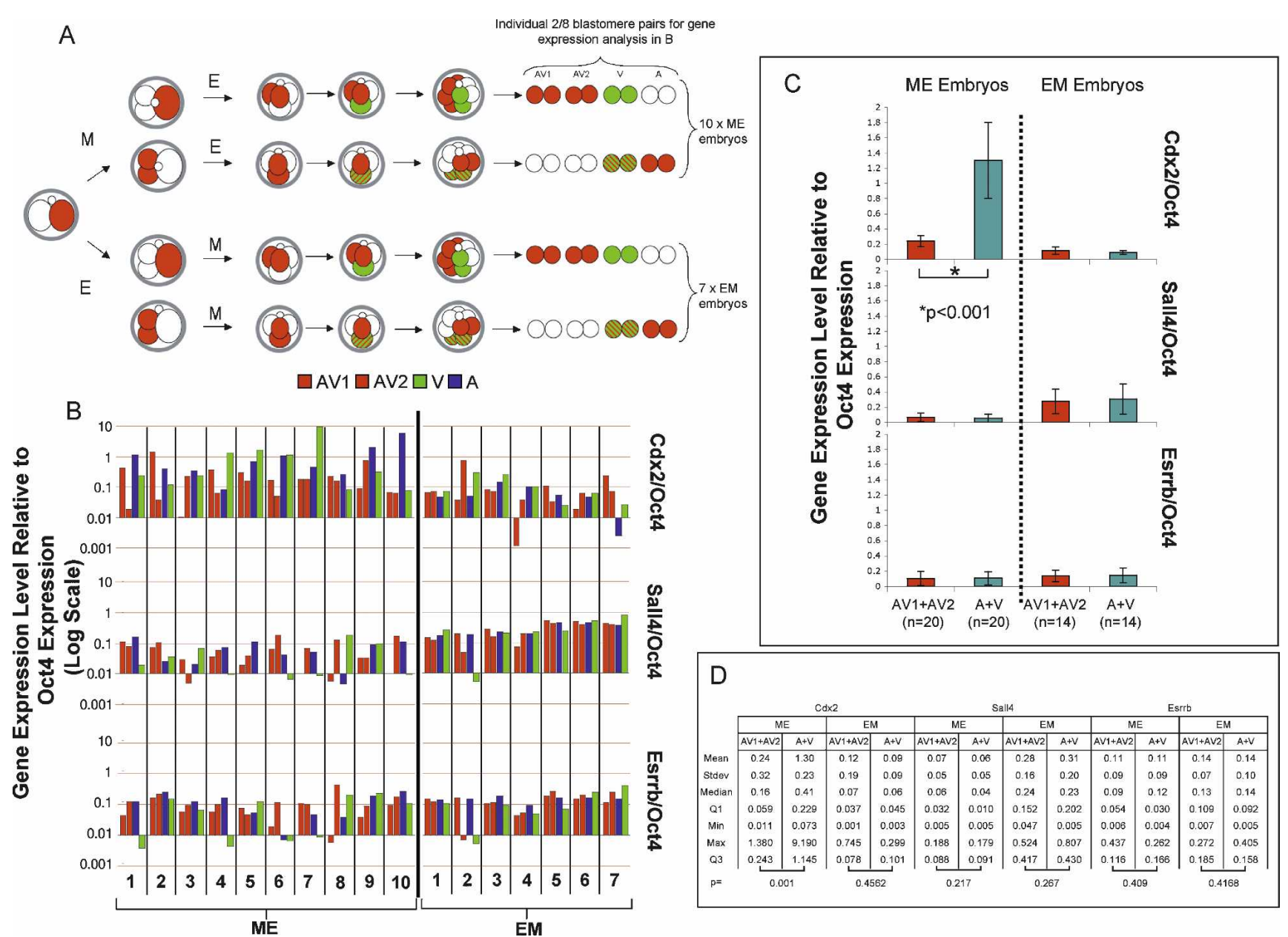

Figure 6. Differential $C d \times 2$ mRNA expression at the eight-cell stage in blastomeres derived from ME and EM embryos. (A) Tracking of blastomere divisions and the harvesting of $2 / 8$ blastomere pairs. One two-cell blastomere was injected with rhodamine dextran. In vitro cultured embryos were observed every 15-20 min and subsequently sorted based on the division plane orientation of the first dividing blastomere, with respect to the AV axis (either $\mathrm{M}$ or $\mathrm{E}$ ) as indicated by the position of the polar body. The second division was similarly classified, thus identifying ME and EM embryos (the few MM and EE embryos were not analyzed). At the four-cell stage, the blastomere in the vegetal (V) position was injected with FITC-conjugated dextran (green). Embryos were cultured until the eight-cell stage had occurred, disaggregated into $4 \times 2 / 8$ pairs per embryo, the pairs were sorted according to type as shown, and total RNA was extracted from each 2/8 pair for gene expression analysis. (B) Taqman real-time PCR analysis of 68 individual 2/8 blastomere pairs (as defined in $A$ ) from $10 \mathrm{ME}$ and seven EM eight-cell embryos. The expression, in technical triplicate, of Oct4, Cdx2, Sall4, and Esrrb was determined in each 2/8 blastomere pair. The data are presented as a ratio against the Oct4 values. Note that the Cdx2:Oct4 ratio is both higher and more variable in ME than EM embryos. (C) The averaged ratios (+SD) of all the AV 2/8 blastomeres compared with those for the all combined A plus V samples shown separately for the ME and EM embryos. Note that for ME-derived 2/8 blastomere pairs, relative $C d x 2$ levels are significantly higher in combined A plus V blastomeres than in AV blastomeres (when distributions are compared in a Mann-Whitney test; $P<0.001)$ and that relative Sall4 levels are lower for the ME-derived 2/8 pairs than for the EM-derived 2/8 pairs regardless of type $(P<0.001$; Student's $t$-test $) .(D)$ Tabulated data from $B$ and $C$ showing mean, median, SD, minimum, maximum, and upper (Q1) and lower (Q3) quartile values for pooled expression data of AV1 plus AV2, and for pooled A plus $\mathrm{V}$ blastomeres in ME and EM embryos. $P$-values are shown for a Mann-Whitney test, between the datasets from $M$ and $\mathrm{E}$ blastomeres within ME and EM embryos.

separately, A plus V pairs, represent 14 biological replicates for EM embryos and 20 biological replicates for ME embryos.

Cdx2 mRNA was below the detection threshold in two-cell embryos, and traces only were detected in fourcell embryos (data not shown), but by the mid four-cell stage, $C d x 2$ expression was detected clearly. Relative to Oct4, its levels were found to be more variable among eight-cell blastomeres from ME than from EM embryos
(Fig. 6B), and, overall, its expression was also significantly higher in ME-derived cells $(P=0.007$; Student's $t$-test to compare means, $P=0.0065$; Mann-Whitney test to compare medians). The variation in Cdx2:Oct4 expression observed among ME-derived blastomeres was due to its significantly elevated expression in the A and V blastomeres derived from $\mathrm{E}$ divisions compared with that in M-derived AV blastomeres (Mann-Whitney test, $P=0.001$ ) (Fig. 6C,D). This expression was 5.4 times 
higher in $\mathrm{E}$ than $\mathrm{M}$ blastomeres. This finding paralleled the immunocytological results (Fig. 5). No such differences were observed for control (Sall4:Oct4 and Esr$r b: O c t 4)$ ratios, although ME-derived cells were distinguishable overall from EM-derived cells by their lower Sall4:Oct4 ratios $(P<0.001$; Student's $t$-test, $P=0.023$; Mann-Whitney test). Thus, at both protein and mRNA levels, ME-derived embryos can be distinguished from EM-derived embryos by the fact that, in the former, cells resulting from $\mathrm{E}$ divisions showed significantly stronger expression of $C d x 2$. Thus, the expression of $C d \times 2$ at the eight-cell stage does not appear to be initiated at random, but in relation to the lineage of cells.

$\mathrm{Cdx} 2 \mathrm{mRNA}$ becomes localized apically at the eightand 16-cell stages and so is distributed asymmetrically upon differentiative divisions

The ability to detect $C d x 2$ transcripts at the eight-cell stage by real-time PCR led us to examine the question of whether their spatial distribution could be visualized by fluorescent in situ hybridization. $C d \times 2$ transcripts were strongly detected in blastocysts $(n=12)$ being restricted, as expected, to the trophectoderm (Supplemental Fig. 4; Supplemental Material). Again, we found no convincing evidence of $C d x 2$ expression prior to the eight-cell stage $(n=10)$ (Fig. 7F). However, at the eight-cell $(n=12)$ (Fig. 7A-C) and 12- to 16-cell $(n=36)$ (Fig. 7D) stages, $C d x 2$ mRNA transcripts were clearly detectable and appeared more abundant in a subset of cells (sense controls showing no signal, Fig. 7E). Most interestingly, we found that the $C d \times 2$ transcripts were concentrated in the apical domains of eight- and outer 16-cell blastomeres (Fig. 7A$D, G)$. To further ensure the specificity of this localization, we down-regulated $C d x 2$ expression by RNAi in one of the two-cell blastomeres and could, as expected, see the in situ signal clearly only in half of the cells of the eight-cell stage embryo (Fig. 7H). Moreover, this apical localization was not seen for transcripts of genes encoding other transcription factors that are important for
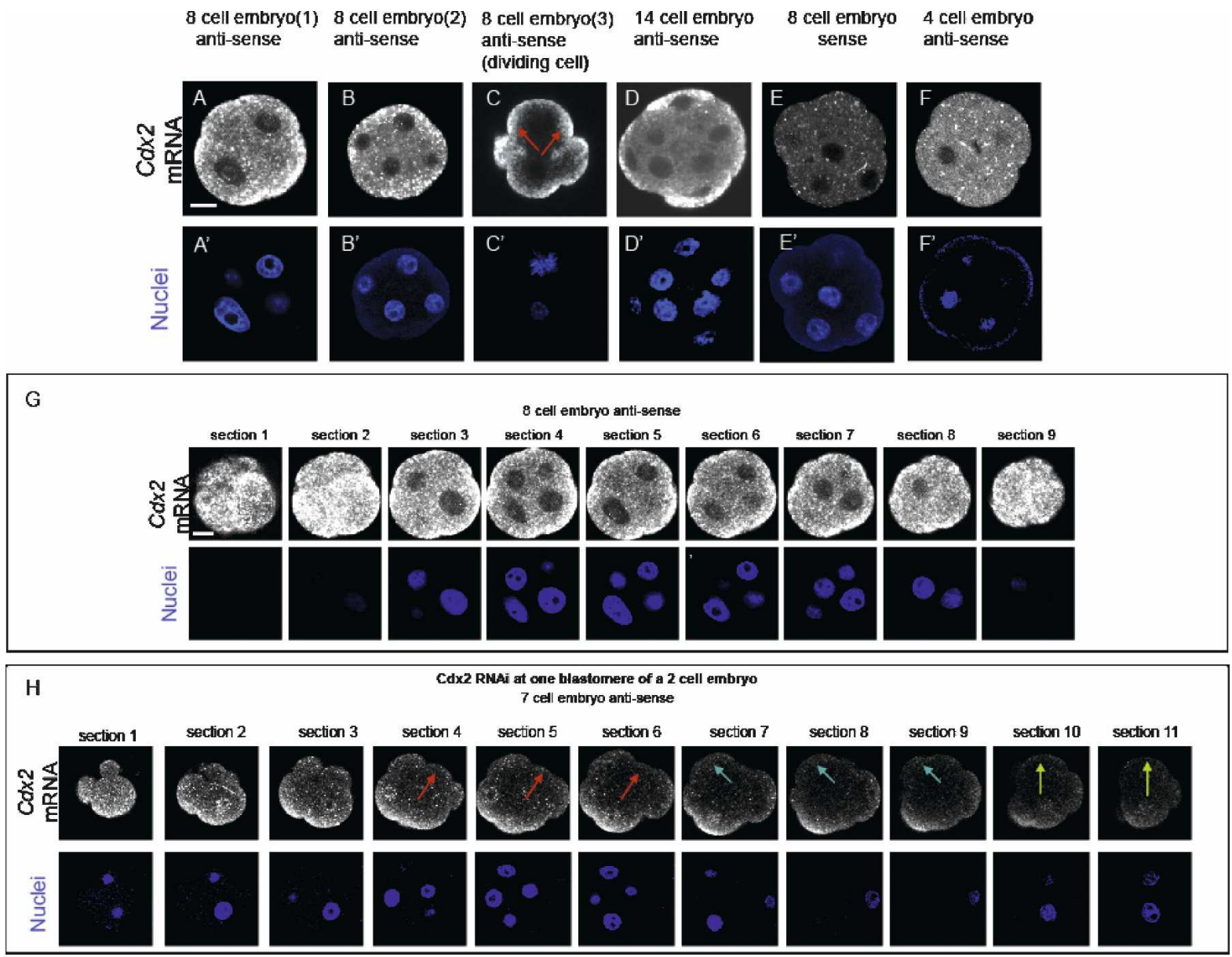

Figure 7. Apical localization of $C d x 2$ mRNA in eight- and 16-outer-cell blastomeres. Fluorescent whole-mount in situ hybridization for mRNA. Each section is taken in a central plane through the embryo and visualized either for RNA or for nucleus stained by DAPI $(') \cdot(A-D)$ Apical localization of $C d x 2$ mRNA in eight- to 16-cell embryos using the antisense probe. $(C)$ Note retention of apical localization in mitotic cell. $(E)$ Control using sense probe. $(F)$ Four-cell stage with no clear signal. $(G) C d x 2$ mRNA in consecutive sections through one eight-cell embryo to show apical location. $(H) C d x 2$ mRNA in embryos in which dsRNA for $C d x 2$ had been injected into one late two-cell-stage blastomere. (Red and blue arrows) Progeny of injected blastomeres that lack signal. Bar, 10 um. 
cell commitment and expressed at this stage. Neither Sox2 nor Nanog transcripts were located apically (Supplemental Figs. 5, 6). Thus, the polarized distribution of message along the apico-basal axis of eight- and 16-cell blastomeres appears specific to $C d x 2$. Examination of blastomeres in which mitotic figures were evident revealed that in each cell this polarized distribution of $C d x 2$ mRNA remained evident during cell division (Fig. 7C). This means that symmetric divisions of eight- and 16cell blastomeres are likely to provide both daughter cells with a similar amount of $C d \times 2$ message, while differentiative divisions would generate an outside daughter cell with relatively more $C d x 2$ mRNA than her inside sister cell. Thus, divisions generating inside and outside cells are truly asymmetric as they distribute the message of the cell fate-determining gene asymmetrically between the daughter cells. This unequal distribution would contribute to breaking the symmetry between inside and outside cells and so could lead to the lineage diversification.

\section{Discussion}

This paper addresses the allocation to, and specification of, cells as trophectoderm or ICM and suggests a relationship between the two processes. Specifically, we examined the nature and timing of the influence of $\mathrm{Cdx} 2$ on trophectoderm development. Our data indicate that (1) elevated expression of $C d x 2$ by the eight-cell stage stimulates a greater allocation of cells to adopt outside positions by promoting symmetric divisions and thus leads to an increased contribution of cells to the trophectoderm; (2) this effect may be mediated, at least in part, through aPKC activity in the $C d x$ 2-expressing cells; (3) conversely, the clonal down-regulation of $C d x 2$ results in cells making a proportionally reduced contribution to the outer compartment by undertaking more asymmetric divisions; and (4) the distribution of $C d \times 2$ mRNA is polarized in eight-cell and outer 16-cell blastomeres, and this polar distribution persists during cell division, providing one possible explanation for the nature of the link between cell allocation and cell specification. We also find that the division pattern and thus cellular partitioning at the second cleavage influences the expression of $C d x 2$ mRNA and its protein at the eight-cell stage, and that these differences in expression pattern can influence allocation and specification in the nonmanipulated embryo. Our data suggest that the onset of $C d x 2$ expression and cell polarization may be interlinked to affect cell allocation to inside and outside positions as well as the later specification events to ensure the generation of a stable outer epithelium by the blastocyst stage.

Our observation that directed expression of $C d x 2$ in part of the embryo leads to an increased allocation of these cells to the outer cell population through an increased incidence of symmetric divisions is, to our knowledge, the first evidence in the mouse embryo that manipulation of a cell fate-associated transcription factor can influence division orientation. Although such an influence could be exerted directly on the spindle, it seems likely that the effect is in part indirect through an influence on cellular polarity_for example, via Par3 or aPKC (Plusa et al. 2005a) _ and this might affect apical pole size (Pickering et al. 1988). Interestingly, therefore, we find that $C d x 2$ up-regulation is associated with an increased expression of aPKC, a molecule that itself becomes polarized at the eight-cell stage. The direct down-regulation of aPKC was shown previously to increase cell allocation to the inside position (Plusa et al. 2005a), an observation consistent with our current findings. It is of interest that the aPKC gene has in its potential regulatory sequences a consensus binding site for Cdx2 (our unpublished data).

It has recently been shown that cells lacking $C d x 2$ can still contribute to the outside part of the embryo in chimeras and that aPKC is initially localized apically in these cells (Ralston and Rossant 2008), which indicates that aPKC expression cannot be exclusively dependent on $C d x 2$. We also find here that following depletion of $C d x 2$ in part of the embryo by RNAi, cells can still remain outside. There is, however, a difference between Ralston and Rossants' report (Ralston and Rossant 2008) and the present study. While both papers indicate that cells without $\mathrm{Cdx} 2$ can localize outside, our data indicate that such $\mathrm{Cdx} 2$-depleted cells are less likely to do so-they have preference to give rise to more ICM cells than their neighbors. Conversely, we find that cells with higher levels of $\mathrm{Cdx} 2$ are less likely to be allocated to the inside position and thus to form the ICM. Furthermore, tracking all individual cells in normal development has shown that the natural heterogeneity in Cdx2 levels at the eight-cell stage has similar consequences: cells with naturally higher levels of $\mathrm{Cdx} 2$ contributing more cells to the trophoectoderm and vice versa (Bischoff et al. 2008). Together, these findings indicate that the level of $\mathrm{Cdx} 2$ expression affects allocation of cells and, consequently, their properties by influencing whether cell division is symmetric or asymmetric. What might be the reasons behind this difference between the observations of Ralston and Rossant (2008) and our own? One possibility is that they might reflect the different experimental approaches used by the two labs, both of which are to some extent invasive. In our case, we microinjected one of the two-cell blastomeres to generate "chimeras," enabling us to compare blastomeres with different Cdx2 levels (up- or down-regulated) that originated from within the same embryo. Ralston and Rossant aggregated $\mathrm{Cdx} 2^{-/-}$ cells together with cells of wild-type embryos, an approach that by its nature disrupts embryo integrity. A second difference between the two studies is of the technique used for experimental analysis. Ralston and Rossant (2008) analyzed the "aggregation chimeras" at later, more mixed stages of blastocyst development at a time when further cell divisions can change the proportions of cells that have been first allocated to the two, inside and outside, compartments. Our studies focused upon early blastocysts immediately after cell allocation is completed and also used time-lapse observations to follow the specific cell divisions allocating cells to inside or outside positions. These approaches reflect the differing objective of the studies; Ralston and Rossant (2008) aimed to 
examine trophectoderm specification, whereas we were addressing allocation of cells to the trophectoderm.

It should be stressed, however, that the data of Ralston and Rossant (2008) and the present study are complementary. The indication from the former that Cdx2 acts downstream from cell polarization is echoed by our finding that $C d x 2$ transcripts become asymmetrically distributed in response to cell polarity. However, our study suggests that, in addition, there is a positive feedback loop between $\mathrm{Cdx} 2$ and cell polarization. This is because increased levels of $\mathrm{Cdx} 2$ in turn lead to the increased apical localization of aPKC. We hypothesize that this feedback loop facilitates the formation of a stable epithelium when the trophectoderm becomes specified. In natural embryonic development, provision of cells with higher $\mathrm{Cdx} 2$ levels that give rise preferentially to trophectoderm lineages and of those with lower Cdx2 levels that are predisposed to make a greater contribution to the ICM might ensure that the process of building the embryo is more successful. Indeed, Cdx2-null trophectoderm is unable to maintain its polarized epithelial integrity and polarized gene expression (Strumpf et al. 2005), consistent with the role proposed for it here in promoting the polar phenotype.

The distinction between allocation and specification of the trophectoderm is one of the central issues addressed by our study, which provides a bridge between currently competing ideas about how the blastocyst forms: the earlier events that bias cell allocation being confirmed by later specifying events. There is now general agreement that the allocation of cells to inside and outside positions is first achieved by the asymmetric divisions of polarized eight-cell blastomeres. This allocation is later followed by the specification of outer or inner cells as trophectoderm or ICM, respectively. Cdx2 plays a critical role in trophectoderm specification (Niwa et al. 2005; Strumpf et al. 2005). As development progresses from the eight-cell stage onward, Cdx2 appears to be up-regulated in outer cells and down-regulated in inner cells by the late 32 -cell stage. Our present data bear on how cell allocation might be related to cell specification. We find that $C d x 2$ mRNA becomes apically enriched within the eight-cell blastomeres as they become polarized, and this distribution is not lost during division. Thus, any division that is asymmetric will lead to an inner population of cells, which inherit less $C d x 2$ mRNA than do outer cells. Ultimately, this might then lead to differential Cdx2 protein levels and to different specification patterns in the two cell populations. Indeed, Cdx2 down-regulates Oct4 and Nanog (Niwa et al. 2005). Whether the apical enrichment of $C d x 2$ mRNA is due to transport (active or passive) or due to spatially regulated differences in transcript stability, is at present unknown.

The early onset of $C d x 2$ expression is linked to the emergence of some developmental patterning that appears to reflect a vestige of some asymmetry that existed in the zygote. Several studies have suggested that differential orientation of early cleavage divisions brings about differential cellular partitioning that influences the distri- bution of cells at the blastocyst stage (Gardner 1997, 2001, 2002, 2007; Piotrowska and Zernicka-Goetz 2001; Piotrowska et al. 2001; Piotrowska-Nitsche and Zernicka-Goetz 2005; Piotrowska-Nitsche et al. 2005; Bischoff et al. 2008). Thus, in the majority of embryos, the first cleavage division is along the AV axis and so distributes both $\mathrm{A}$ and $\mathrm{V}$ material to both daughter blastomeres (Gulyas 1975; Gardner 1997; Plusa et al. 2002, 2005b; Gray et al. 2004). Because of controversy in the early mouse embryo field, it is important to stress that such assessment can be accurate only when the marker of this axis (the second polar body) remains attached to the embryo and before any flow of membrane markers in cytokinesis (Plusa et al. 2005b). It is not possible when the polar body detaches and undertakes extensive movement, as observed in embryos cultured by Hiiragi and Solter (2004). The two-cell blastomeres resulting from the division parallel to the AV axis consequently seem developmentally very similar; mice have been produced from the half embryos derived from them (Tarkowski 1959; Tsunoda and McLaren 1983; Papaioannou et al. 1989). Divisions more perpendicular (equatorial) to the AV axis are first usually observed during the second cleavage divisions. At least one two-cell blastomere divides equatorially in $\sim 90 \%$ of embryos, thereby raising the possibility of a differential distribution of $\mathrm{A}$ and $\mathrm{V}$ parts at this stage (Gardner 2002). Indeed, aggregation chimeras made exclusively from four-cell blastomeres inheriting mainly either A or V parts show significantly compromised development in comparison with chimeras inheriting parts from both poles (Piotrowska-Nitsche et al. 2005). This effect was particularly marked in vegetal-only chimeras, which showed defects in preimplantation development and failed to develop into pups. Moreover, four-cell blastomeres differ in the extent of histone modifications associated with genes that influence cell pluripotency, and these epigenetic differences correlate with the inheritance of the A or V parts from the zygote (Torres-Padilla et al. 2007). These findings raise the possibility that the inheritance of different parts of the zygote might influence the properties of individual blastomeres. There is no suggestion that these early influences specify cells, committing them to different lineages, but they may influence the allocation of cells to different positions and affect their developmental fates. Exactly how this early division pattern might affect later cell allocation is currently unclear, but our present study suggests the interesting possibility that they might operate by influencing the expression levels of a transcription factor implicated in specifying the trophectoderm lineage. Thus, we find that the expression pattern of $C d x 2$ at the eight-cell stage depends upon the division orientation at the two- to four-cell stage. In those cell lineages derived from events in which $\mathrm{A}$ and $\mathrm{V}$ parts are separated by the later second cleavage division, $C d x 2$ expression is elevated at both RNA and protein levels by the eight-cell stage. The RNA differences are particularly intriguing: The $C d \times 2$ :Oct4 ratio is significantly (5.4 times) elevated in blastomeres resulting from E divisions in ME embryos. The Esrrb:Oct4 control val- 
ues do not differ significantly across embryo or blastomere type, as expected for two coexpressing transcription factors (Loh et al. 2006). However, the other control ratio, Sall4:Oct4, shows a significantly depressed expression in all blastomere types from ME embryos. Sall4 is also coexpressed with Oct4 in preimplantation embryos, but acts upstream of it to stimulate Oct4 expression (Zhang et al. 2006). Its down-regulation has been shown to depress Oct4 expression, and to indirectly promote $C d \times 2$ expression and trophectoderm differentiation. The small but significant reduction in the Sall4:Oct4 ratio in ME-derived blastomeres suggests that the cleavage pattern generating ME embryos may not only affect $C d x 2$ expression but also Sall4 expression.

The observation that partitioning of the zygote can influence the level of early $C d x 2$ expression raises the question of whether these differences in $\mathrm{Cdx} 2$ can influence cell allocation in the nonmanipulated embryo. Recent in situ tracking of blastomeres showed that E dividing blastomeres from ME embryos undergo predominantly symmetric divisions and as such contribute predominantly to the trophectoderm (Piotrowska-Nitsche et al. 2005; Bischoff et al. 2008). Here, we show that these cells have significantly elevated levels of Cdx 2 mRNA and protein. That this relationship might be causal is suggested by our observation that progeny of cells showing elevated expression of $C d x 2$ also undertake significantly more symmetric divisions and make a greater contribution to the trophectoderm.

In conclusion, we suggest that not only does the later positioning of cells influence expression of $C d x 2$, but also the early expression of $C d x 2$ can influence polarity and cell positioning. This leads to the idea of a two-step process for generating differences among cells in the mouse embryo in which molecular self-reinforcement may play a role. It allows the progressive building of differences through a metastable precommitment period. The first step would be a result of heterogeneity that develops among cells before the onset of the asymmetric divisions that generate inside cells at the eight-cell stage. The second is a consequence of the asymmetric divisions that set apart inside and outside cell populations. The first step was inferred previously from the significantly reduced developmental potential of cells inheriting different cellular components, rather than components of both poles of the zygote (Piotrowska-Nitsche et al. 2005). The development of these cellular differences along the $\mathrm{AV}$ axis before the eight-cell stage is associated with specific differential epigenetic modifications (Torres-Padilla et al. 2007). Some reports have argued against the existence of these early differences among cells stressing that the prerequisite for the first differences is formation of inside and outside cell populations (Louvet-Vallee et al. 2005; Motosugi et al. 2005; Kurotaki et al. 2007). However, none of these reports has actually examined and compared developmental potential or gene expression of individual blastomeres inheriting different parts of the zygote to substantiate their conclusion. The second step of the two-step process establishing cell diversity occurs with the development of cell polarity at the eight-cell stage, followed by the onset of asymmetric divisions and the inside or outside positioning of cells during the transition to the 32-cell embryo. The inside and outside cells are distinct as a consequence of inheriting different components (Handyside and Johnson 1978; Ziomek and Johnson 1981; Johnson and Ziomek 1982; Louvet et al. 1996; Thomas et al. 2004; Plusa et al. 2005a), as well as in response to their differential positioning within the embryo (Tarkowski and Wroblewska 1967). Interestingly, our study demonstrates that $C d x 2$ mRNA is among the differentially distributed components, and since $C d \times 2$ is a cell fate-determining gene, it seems that the differential divisions can be termed truly asymmetric in terms of cell fate direction. As in step one, the differences between cells generated by this second step (asymmetric divisions) are also initially not determinative and can be reversed in experimental situations (ZernickaGoetz 2005). However, in normal development this spatial and temporal regulation of $C d x 2$, which promotes trophectoderm fate and inhibits expression of the genes involved in ICM specification, ensures that the final outcome is a fully functional blastocyst.

\section{Materials and methods}

All chemicals, unless otherwise stated were from Sigma.

\section{Embryo collection and culture}

Embryos were collected into M2 medium with $4 \mathrm{mg} / \mathrm{mL}$ BSA $(\mathrm{M} 2+\mathrm{BSA})$ from F1 (C57B16 $\times \mathrm{CBA})$ females superovulated with $10 \mathrm{IU}$ of PMSG (Intervet) and $10 \mathrm{IU}$ of hCG (Intervet) $48 \mathrm{~h}$ later and mated with F1, H2B-EGFP (Hadjantonakis and Papa ioannou 2004), or CAG:myr-Venus (Rhee et al. 2006) mice. Embryos were cultured in KSOM with $4 \mathrm{mg} / \mathrm{mL}$ BSA (KSOM + BSA) under paraffin oil in $5 \% \mathrm{CO}_{2}$ at $37.5^{\circ} \mathrm{C}$.

\section{Injection of $m R N A$ and dsRNA for $\mathrm{Cdx} 2$}

A full-length ORF $C d x 2$ DNA construct was cloned into pBluescript RN3P plasmid and prepared as previously described (Zernicka-Goetz et al. 1997). To overexpress Cdx2, one blastomere was injected with mRNA for $C d \times 2(50 \mathrm{ng} / \mathrm{\mu L})$ and $\operatorname{DsRed}(0.3 \mu \mathrm{g} / \mu \mathrm{L})$ or, in controls, DsRed alone. To down-regulate $C d \times 2$, dsRNA was synthesized in vitro using T7 RNA polymerase (Ambion). A PCR using the construct described above, using primers specific to T7 RNA polymerase core sequence, synthesized the template Primer Cdx2T7-F, TAATACGAC TCACTATAGGAACCTGGCTCCGCAGAACTTTG; Primer Cdx2T7-R, TAATACGACTCACTATAGGTTCCTCCTGAT GGTGATGTATCG.

Embryos were cultured until the blastocyst stage and then observed under an inverted confocal microscope. Sections were recorded every $0.4 \mu \mathrm{m}$ (Supplemental Movie 1).

\section{Time-lapse imaging and analysis}

Lineages were followed by time-lapse microscopy and analyzed with SIMI Biocell software (for details, see Bischoff et al. 2008). Initiation of cell division was defined as the start of cleavage furrow ingression (in DIC images) and metaphase formation (in fluorescence images). To examine whether the division was symmetric or asymmetric, coordinates of cells were saved one frame (15 $\mathrm{min}$ ) before division, and two frames later to determine the position of its daughters in relation to the embryo 
surface, and were analyzed as described before (Supplemental Fig. 3; Bischoff et al. 2008).

\section{Immunocytochemical staining}

Embryos were fixed in 5\% PFA for $20 \mathrm{~min}$ at $37^{\circ} \mathrm{C}$ and treated for immunofluorescence as in Plusa et al. (2005a). Cdx2 was visualized using mouse antibody (mouse monoclonal; BioGenex) at 1:200 in BSA/Tween and AlexaFluor 488-conjugated anti-mouse antibody at 1:500 (Jackson ImmunoResearch Laboratories). For aPKC, rabbit antibody (Santa Cruz Biotechnologies) at 1:200 and AlexaFluor 488-conjugated anti-rabbit antibody at 1:200 (Invitro-

gen) were used. After antibody incubations and washes, embryos were mounted in DAPI-Vectashield on polylysine slides. Cells were imaged on a Zeiss510 Multiphoton confocal microscope. To analyze the time course of $\mathrm{Cdx} 2$ expression at the eight-cell stage, embryos were collected $55 \mathrm{~h}$ post-hCG (mid to late four-cell stage), cultured in KSOM, and checked every hour for division to eight cells. Embryos were fixed at 4-5, 7-8, or 9-10 h after eight-cell onset. To analyze whether early division patterns influence $\mathrm{Cdx} 2$ expression, one two-cell blastomere was injected with rhodamine dextran (Molecular Probes), transferred to KSOM, and checked every $15 \mathrm{~min}$ to score second cleavage division orientations. Embryos were sorted into ME or EM groups (Results), and then according to blastomeres' positivity $(+)$ for rhodamine dextran: $M+E, M E+, E+M$, and $E M+$. Groups of embryos were fixed 7-8 h after the onset of the eightcell stage and immunostained as above. Staining was scored blind-to-group-type by two independent observers as being weak or strong.

\section{Fluorescent whole-mount in situ hybridization}

Embryos were fixed with $4 \%$ PFA in PBS overnight at $4{ }^{\circ} \mathrm{C}$, stored in methanol at $-20^{\circ} \mathrm{C}$, and then bleached in $100 \%$ $\mathrm{MetOH} / 30 \%$ hydrogen peroxide (4:1) for $1 \mathrm{~h}$ at room temperature. In situ hybridization was performed according to Chazaud et al. (2006) with some modifications (see the Supplemental Material).

\section{Typing and collection of eight-cell blastomeres for RT-PCR}

Embryos were collected and sorted into ME and EM groups as described above. All embryos analyzed had reached the four-cell stage within $10-11 \mathrm{~h}$ of culture. The vegetally positioned fourcell blastomere from E divisions was then injected with FITCdextran 10-12 h after division of the first blastomere. Embryos were then observed every $1 \mathrm{~h}$ for their development to eight cells. Six hours to $7 \mathrm{~h}$ after this, zonae were removed with $0.5 \%$ pronase in PBS, the embryos were incubated in $\mathrm{Ca}^{2+} / \mathrm{Mg}^{2+}$-free M2 for $3 \mathrm{~min}$, and their blastomeres were separated into 2/8 pairs by pipetting. Pairs were segregated as $M$ (meridional, AV1, or AV2), A, and V based on the presence of red or green dextran, placed into their own tubes containing $10 \mu \mathrm{L}$ of RNA extraction buffer, and snap frozen until used in RT-PCR. Since A and V blastomeres can rotate during division (Piotrowska-Nitsche et al. 2005), about half of the blastomeres in the $\mathrm{V}$ position might in fact be A blastomeres and vice versa (AV blastomeres are distinguishable unambiguously). It was not possible to control for this rotation in this study.

RNA isolation, reverse transcription, preamplification, and real-time PCR analysis

Total RNA was extracted from pairs of blastomeres using the PicoPure RNA isolation kit (Arcturus Bioscience) and used for cDNA synthesis in the high-capacity cDNA archive kit (Applied Biosystems). A third of each cDNA preparation was preamplified in a total volume of $25 \mu \mathrm{L}$ for genes of interest by 18 cycles of amplification (each cycle: $15 \mathrm{sec}$ at $95^{\circ} \mathrm{C}$ and 4 min at $60^{\circ} \mathrm{C}$ ) using the TaqMan PreAmp Master Mix Kit (Applied Biosystems). Products were diluted 10-fold, and $5 \mu \mathrm{L}$ from each was used for analysis. Real-time reactions were performed in technical triplicate with master mix (Applied Biosystems) in 48.48 Dynamic Array on a BioMark System (Fluidigm). Threshold cycle $(\mathrm{Ct})$ values were calculated from the system's software (BioMark Real-time PCR Analysis) and used as a direct measure of gene expression. A Ct value of 29 was set as background, as the highest reproducible Ct value of all samples was 28.7. Variance was calculated in Excel (Microsoft). TaqMan real-time primer probe sets (Applied Biosystems) were as follows: Oct4, Mm00658129_gH; Cdx2, Mm00432449_m1; Sall4, Mm00453037_s1; Esrrb, Mm00442411_m1. Cdx2 Ct values were normalized against Oct4 Ct values for the same sample, as evidence suggests that this ratio is critical for lineage specification (Niwa et al. 2005). As controls, we used Esrrb:Oct4 and Sall4:Oct4 ratios. Esrrb is a pluripotency-related gene that is downstream of Oct4 (Loh et al. 2006). Sall4 acts upstream to regulate Oct4 expression, modulating pluriblast/trophoblast specification (Zhang et al. 2006). Down-regulation of Sall4 depresses Oct4 expression, and promotes $C d x 2$ expression and trophoblast differentiation. Both of these control mRNAs might therefore be expected to be ratiometrically stable with respect to Oct4.

\section{Statistical analysis}

The fourfold $\chi^{2}$ test $(\mathrm{df}=1)$ was used to analyze differences in the intensity of immunofluorescence staining. Student's $t$-Test and Mann-Whitney test were used to analyze the differences in qRT-PCR data. The Mann-Whitney test was used to analyze the $\mathrm{Cdx} 2$ elevation and down-regulation data.

\section{Acknowledgments}

This study is dedicated to Dr. Anne McLaren, a wonderful colleague and advisor, as a mark of respect for her work. We are grateful to Claire Chazaud for advice on in situ hybridization, Janet Rossant and David Glover for helpful discussion and comments on the manuscript, Kat Hadjantonakis and Ginny Papaioannou for reporter transgenic lines, and Jedrzej Chwiejczak for statistical analysis. This work has been supported by the Wellcome Trust Senior Research Fellowship and BBSRC grant to M.Z.G., and a Singapore Stem Cell Consortium grant to P.R. A.J. carried out experiments to modulate the $C d x 2$ expression levels. D.-E.P. examined the spatial distribution of $\mathrm{Cdx} 2$ protein and mRNA levels. G.G. and P.R. quantitatively analyzed levels of Cdx2, Oct4, Sall4, and Esrrb in blastomeres depending on their origin. M.S. carried out FISH experiments. J.G. participated in the blastomere collection to examine their expression profiles. M.H.J. cosupervised the project and contributed to writing. M.Z.-G. conceived, coordinated, and supervised the project, provided funding, and wrote the paper.

\section{References}

Avilion, A.A., Nicolis, S.K., Pevny, L.H., Perez, L., Vivian, N., and Lovell-Badge, R. 2003. Multipotent cell lineages in early mouse development depend on SOX2 function. Genes \& Dev. 17: 126-140.

Bischoff, M., Parfitt, D.E., and Zernicka-Goetz, M. 2008. For- 
mation of the embryonic-abembryonic axis of the mouse blastocyst: Relationships between orientation of early cleavage divisions and pattern of symmetric/asymmetric divisions. Development 135: 953-962.

Chazaud, C., Yamanaka, Y., Pawson, T., and Rossant, J. 2006. Early lineage segregation between epiblast and primitive endoderm in mouse blastocysts through the Grb2-MAPK pathway. Dev. Cell 10: 615-624.

Ciruna, B. and Rossant, J. 2001. FGF signalling regulates mesoderm cell fate specification and morphogenetic movement at the primitive steak. Dev. Cell 1: 37-49.

Dietrich, J.E. and Hiiragi, T. 2007. Stochastic patterning in the mouse pre-implantation embryo. Development 134: 42194231.

Gardner, R.L. 1997. The early blastocyst is bilaterally symmetrical and its axis of symmetry is aligned with the animal-vegetal axis of the zygote in the mouse. Development 124: 289-301.

Gardner, R.L. 2001. Specification of embryonic axes begins before cleavage in normal mouse development. Development 128: $839-847$.

Gardner, R.L. 2002. Experimental analysis of second cleavage in the mouse. Hum. Reprod. 17: 3178-3189.

Gardner, R.L. 2007. The axis of polarity of the mouse blastocyst is specified before blastulation and independently of the zona pellucida. Hum. Reprod. 22: 798-806.

Gray, D., Plusa, B., Piotrowska, K., Na, J., Tom, B., Glover, D.M., and Zernicka-Goetz, M. 2004. First cleavage of the mouse embryo responds to change in egg shape at fertilization. Curr. Biol. 14: 397-405.

Gulyas, B.J. 1975. A reexamination of cleavage patterns in eutherian mammalian eggs: Rotation of blastomere pairs during second cleavage in the rabbit. J. Exp. Zool. 193: 235-248.

Hadjantonakis, A.K. and Papaioannou, V.E. 2004. Dynamic in vivo imaging and cell tracking using a histone fluorescent protein fusion in mice. BMC Biotechnol. 4: 33. doi: 10.1186/ 1472-6750-4-33.

Handyside, A.H. and Johnson, M.H. 1978. Temporal and spatial patterns of the synthesis of tissue-specific polypeptides in the preimplantation mouse embryo. J. Embryol. Exp. Morphol. 44: 191-199.

Hiiragi, T. and Solter, D. 2004. First cleavage plane of the mouse egg is not predetermined but defined by the topology of the two apposing pronuclei. Nature 6997: 360-364.

Johnson, M.H. and McConnell, J.M. 2004. Lineage allocation and cell polarity during mouse embryogenesis. Semin. Cell Dev. Biol. 15: 583-597.

Johnson, M.H. and Ziomek, C.A. 1982. Cell subpopulations in the late morula and early blastocyst of the mouse. Dev. Biol. 91: 431-439.

Kurotaki, Y., Hatta, K., Nakao, K., Nabeshima, Y., and Fujimori, T. 2007. Blastocyst axis is specified independently of early cell lineage but aligns with the ZP shape. Science 316: 719723.

Loh, Y.H., Wu, Q., Chew, J.L., Vega, V.B., Zhang, W., Chen, X., Bourque, G., George, J., Leong, B., Liu, J., et al. 2006. The Oct4 and Nanog transcription network regulates pluripotency in mouse embryonic stem cells. Nat. Genet. 38: 431-440.

Louvet, S., Aghion, J., Santa-Maria, A., Mangeat, P., and Maro, B. 1996. Ezrin becomes restricted to outer cells following asymmetrical division in the preimplantation mouse embryo. Dev. Biol. 177: 568-579.

Louvet-Vallee, S., Vinot, S., and Maro, B. 2005. Mitotic spindles and cleavage planes are oriented randomly in the two-cell mouse embryo. Curr. Biol. 15: 464-469.

Motosugi, N., Bauer, T., Polanski, Z., Solter, D., and Hiiragi, T.
2005. Polarity of the mouse embryo is established at blastocyst and is not prepatterned. Genes \& Dev. 19: 1081-1092.

Nishioka, N., Yamamoto, S., Kiyonari, H., Sato, H., Sawada, A., Ota, M., Nakao, K., and Sasaki, H. 2008. Tead4 is required for specification of trophectoderm in pre-implantation mouse embryos. Mech. Dev. 125: 270-283.

Niwa, H., Toyooka, Y., Shimosato, D., Strumpf, D., Takahashi, K., Yagi, R., and Rossant, J. 2005. Interaction between Oct $3 / 4$ and $\mathrm{Cdx} 2$ determines trophectoderm differentiation. Cell 123: 917-929.

Papaioannou, V.E., Mkandawire, J., and Biggers, J.D. 1989. Development and phenotypic variability of genetically identical half mouse embryos. Development 106: 817-827.

Pickering, S.J., Maro, B., Johnson, M.H., and Skepper, J.N. 1988. The influence of cell contact on the division of mouse 8-cell blastomeres. Development 103: 353-363.

Piotrowska, K. and Zernicka-Goetz, M. 2001. Role for sperm in spatial patterning of the early mouse embryo. Nature 409: 517-521.

Piotrowska, K., Wianny, F., Pedersen, R.A., and ZernickaGoetz, M. 2001. Blastomeres arising from the first cleavage division have distinguishable fates in normal mouse development. Development 128: 3739-3748.

Piotrowska-Nitsche, K. and Zernicka-Goetz, M. 2005. Spatial arrangement of individual 4-cell stage blastomeres and the order in which they are generated correlate with blastocyst pattern in the mouse embryo. Mech. Dev. 122: 487-500.

Piotrowska-Nitsche, K., Perea-Gomez, A., Haraguchi, S., and Zernicka-Goetz, M. 2005. Four-cell stage mouse blastomeres have different developmental properties. Development 132: 479-490.

Plusa, B., Grabarek, J.B., Piotrowska, K., Glover, D.M., and Zernicka-Goetz, M. 2002. Site of the previous meiotic division defines cleavage orientation in the mouse embryo. Nat. Cell Biol. 4: 811-815.

Plusa, B., Frankenberg, S., Chalmers, A., Hadjantonakis, A.K., Moore, C.A., Papalopulu, N., Papaioannou, V.E., Glover, D.M., and Zernicka-Goetz, M. 2005a. Downregulation of Par3 and aPKC function directs cells towards the ICM in the preimplantation mouse embryo. J. Cell Sci. 118: 505-515.

Plusa, B., Hadjantonakis, A.K., Gray, D., Piotrowska-Nitsche, K., Jedrusik, A., Papaioannou, V.E., Glover, D.M., and Zernicka-Goetz, M. 2005b. The first cleavage of the mouse zygote predicts the blastocyst axis. Nature 434: 391-395.

Ralston, A. and Rossant, J. 2008. Cdx2 acts downstream of cell polarization to cell-autonomously promote trophectoderm fate in the early mouse embryo. Dev. Biol. 313: 614-629.

Rhee, J.M., Pirity, M.K., Lackan, C.S., Long, J.Z., Kondoh, G., Takeda, J., and Hadjantonakis, A.K. 2006. In vivo imaging and differential localization of lipid-modified GFP-variant fusions in embryonic stem cells and mice. Genesis 44: 202218.

Rossant, J. 2004. Lineage development and polar asymmetries in the peri-implantation mouse blastocyst. Semin. Cell Dev. Biol. 15: 573-581.

Smith, A. 2005. The battlefield of pluripotency. Cell 123: $757-$ 760.

Strumpf, D., Mao, C.A., Yamanaka, Y., Ralston, A., Chawengsaksophak, K., Beck, F., and Rossant, J. 2005. Cdx2 is required for correct cell fate specification and differentiation of trophectoderm in the mouse blastocyst. Development 132: 2093-2102.

Tarkowski, A.K. 1959. Experiments on the development of isolated blastomers of mouse eggs. Nature 184: 1286-1287.

Tarkowski, A.K. and Wroblewska, J. 1967. Development of blastomeres of mouse eggs isolated at the 4- and 8-cell stage. $J$. Embryol. Exp. Morphol. 18: 155-180. 
Jedrusik et al.

Thomas, F.C., Sheth, B., Eckert, J.J., Bazzoni, G., Dejana, E., and Fleming, T.P. 2004. Contribution of JAM-1 to epithelial differentiation and tight-junction biogenesis in the mouse preimplantation embryo. J. Cell Sci. 117: 5599-5608.

Torres-Padilla, M.E., Parfitt, D.E., Kouzarides, T., and ZernickaGoetz, M. 2007. Histone arginine methylation regulates pluripotency in the early mouse embryo. Nature 445: 214-218.

Tsunoda, Y. and McLaren, A. 1983. Effect of various procedures on the viability of mouse embryos containing half the normal number of blastomeres. J. Reprod. Fertil. 69: 315-322.

Yagi, R., Kohn, M.J., Karavanova, I., Kaneko, K.J., Vullhorst, D., Depamphilis, M.L., and Buonanno, A. 2007. Transcription factor TEAD4 specifies the trophectoderm lineage at the beginning of mammalian development. Development 134: 3827-3836.

Zernicka-Goetz, M. 2004. First cell fate decisions and spatial patterning in the early mouse embryo. Semin. Cell Dev. Biol. 15: 563-572.

Zernicka-Goetz, M. 2005. Cleavage pattern and emerging asymmetry of the mouse embryo. Nat. Rev. Mol. Cell Biol. 6: 919-928.

Zernicka-Goetz, M., Pines, J., McLean Hunter, S., Dixon, J.P., Siemering, K.R., Haseloff, J., and Evans, M.J. 1997. Following cell fate in the living mouse embryo. Development 124: 1133-1137.

Zhang, J., Tam, W.L., Tong, G.Q., Wu, Q., Chan, H.Y., Soh, B.S., Lou, Y., Yang, J., Ma, Y., Chai, L., et al. 2006. Sall4 modulates embryonic stem cell pluripotency and early embryonic development by the transcriptional regulation of Pou5f1. Nat. Cell Biol. 8: 1114-1123.

Ziomek, C.A. and Johnson, M.H. 1981. Properties of polar and apolar cells from the 16-cell mouse morula. Rouxs Arch. Dev. Biol. 190: 287-296. 


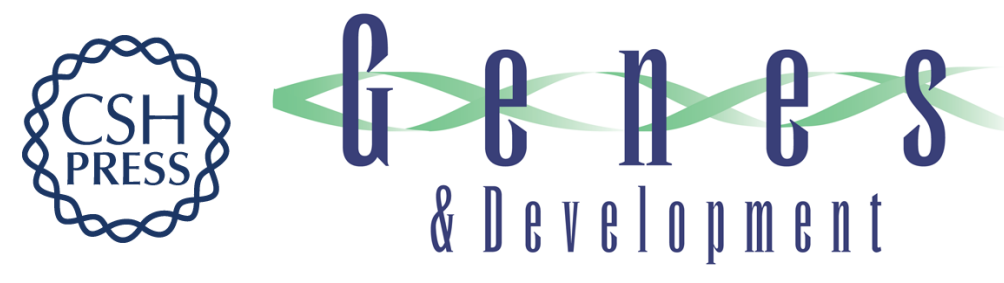

\section{Role of Cdx2 and cell polarity in cell allocation and specification of trophectoderm and inner cell mass in the mouse embryo}

Agnieszka Jedrusik, David-Emlyn Parfitt, Guoji Guo, et al.

Genes Dev. 2008, 22:

Access the most recent version at doi:10.1101/gad.486108

Supplemental
Material http://genesdev.cshlp.org/content/suppl/2008/09/22/22.19.2692.DC1

References This article cites 48 articles, 17 of which can be accessed free at:

http://genesdev.cshlp.org/content/22/19/2692.full.html\#ref-list-1

License

Email Alerting

Receive free email alerts when new articles cite this article - sign up in the box at the top

Service

right corner of the article or click here.

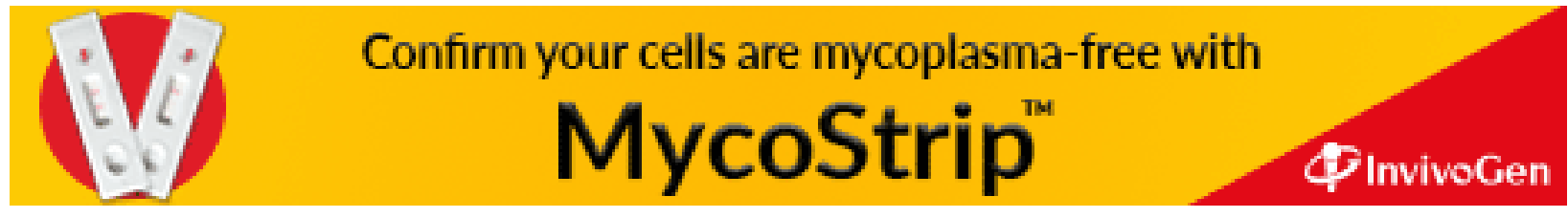

